\title{
Subscapular skinfold thickness distinguishes between transient and persistent impaired glucose tolerance: Study on Lifestyle-Intervention and Impaired Glucose Tolerance Maastricht (SLIM)
}

Citation for published version (APA):

Mensink, M. R., Feskens, E., Kruijshoop, M., de Bruin, T. W. A., Saris, W. H. M., \& Blaak, E. E. (2003). Subscapular skinfold thickness distinguishes between transient and persistent impaired glucose tolerance: Study on Lifestyle-Intervention and Impaired Glucose Tolerance Maastricht (SLIM). Diabetic Medicine, 20(7), 552-557. https://doi.org/10.1046/j.1464-5491.2003.00962.x

Document status and date:

Published: 01/01/2003

DOI:

10.1046/j.1464-5491.2003.00962.x

Document Version:

Publisher's PDF, also known as Version of record

Please check the document version of this publication:

- A submitted manuscript is the version of the article upon submission and before peer-review. There can be important differences between the submitted version and the official published version of record. People interested in the research are advised to contact the author for the final version of the publication, or visit the DOI to the publisher's website.

- The final author version and the galley proof are versions of the publication after peer review.

- The final published version features the final layout of the paper including the volume, issue and page numbers.

Link to publication

\footnotetext{
General rights rights.

- You may freely distribute the URL identifying the publication in the public portal. please follow below link for the End User Agreement:

www.umlib.nl/taverne-license

Take down policy

If you believe that this document breaches copyright please contact us at:

repository@maastrichtuniversity.nl

providing details and we will investigate your claim.
}

Copyright and moral rights for the publications made accessible in the public portal are retained by the authors and/or other copyright owners and it is a condition of accessing publications that users recognise and abide by the legal requirements associated with these

- Users may download and print one copy of any publication from the public portal for the purpose of private study or research.

- You may not further distribute the material or use it for any profit-making activity or commercial gain

If the publication is distributed under the terms of Article 25fa of the Dutch Copyright Act, indicated by the "Taverne" license above,

Download date: 26 Apr. 2023 


\title{
Subscapular skinfold thickness distinguishes between transient and persistent impaired glucose tolerance: Study on Lifestyle-Intervention and Impaired Glucose Tolerance Maastricht (SLIM)
}

\author{
M. Mensink, E. J. M. Feskens*, M. Kruijshoopt, T. W. A. de Bruint, W. H. M. Saris and \\ E. E. Blaak
}

Department of Human Biology, Nutrition and Toxicology Research Institute (NUTRIM), Maastricht University, Maastricht, *Department of Nutrition and Health, National Institute of Public Health and the Environment, Bilthoven, and tDepartment of Medicine and Endocrinology, University Hospital Maastricht, Maastricht, the Netherlands

Accepted 19 February 2003

\begin{abstract}
Aims To assess whether adding anthropometric measurements to an oral glucose tolerance test (OGTT) can help to distinguish between transient and persistent impaired glucose tolerance (IGT).

Methods From the SLIM project (Study on Lifestyle-Intervention and IGT Maastricht), a study designed to evaluate whether diet and physical activity intervention can improve glucose tolerance in subjects at risk for diabetes, 108 subjects with IGT underwent a repeated OGTT 2-4 months after the initial OGTT. Following the second test, subjects were classified as transient IGT, or persistent IGT. Anthropometric measurements, including body mass index, waist and hip circumference, sagittal and transverse abdominal diameters and skinfold thickness measurements, were done during the second OGTT.
\end{abstract}

Results Persistent IGT was diagnosed in 47 subjects (44\%), transient IGT in $40(37 \%)$, impaired fasting glucose in eight subjects $(7 \%)$, and diabetes in 13 cases $(12 \%)$. Two-hour blood glucose levels at the initial OGTT and subscapular skinfold thickness were significantly higher in subjects with persistent IGT (2-h blood glucose $9.8 \pm 0.1 \mathrm{mmol} / \mathrm{l}$ vs. $10.2 \pm 0.1 \mathrm{mmol} / \mathrm{l}$ for transient IGT and persistent IGT, respectively; subscapular skinfold thickness $25.4 \pm 1.4 \mathrm{~mm}$ vs. $29.8 \pm 1.2 \mathrm{~mm}$ for transient IGT and persistent IGT, respectively). After adjustment for age, sex and family history of diabetes mellitus, logistic regression indicated that 2-h blood glucose level during the initial OGTT represented the strongest predictor of persistent IGT $(P<0.02)$, followed by subscapular skinfold thickness $(P<0.05)$. After adjustment for 2 -h blood glucose levels during the first OGTT, subscapular skinfold thickness remained significantly associated with persistent IGT (odds ratio 1.84; $P<0.05$ ).

Conclusions In addition to the 2 -h blood glucose level, subscapular skinfold thickness was the best predictor of persistent IGT, suggesting that adding simple anthropometric measures to oral glucose tolerance testing may improve the distinction between persistent and transient glucose intolerance.

Diabet. Med. 20, 552-557 (2003)

Keywords impaired glucose tolerance, obesity, body fat distribution, blood glucose 


\section{Introduction}

Impaired glucose tolerance (IGT) is considered a precursor to Type 2 diabetes mellitus. Prevalence of IGT varies widely between populations, from as low as $2.0 \%$ in rural populations to $>20 \%$ in high-risk populations [1]. Cumulative incidence of diabetes ranges from $23 \%$ up to $63 \%$ among subjects with IGT [2], and is strongly dependent on baseline fasting and 2-h glucose concentration [3]. IGT is also associated with adverse cardiovascular risk factors, and an increased risk of cardiovascular disease $[4,5]$. Subjects with IGT benefit from (early) lifestyle interventions, aimed at the prevention or delay of progression to Type 2 diabetes mellitus and cardiovascular disease [6,7].

IGT is identified with an oral glucose tolerance test (OGTT), but about $50 \%$ of the subjects revert to normal glucose tolerance at re-testing, indicating a poor reproducibility [8,9]. Subjects with IGT on two occasions, known as persistent IGT, have a higher risk of developing diabetes compared with those returning to normal glucose tolerance at re-testing (transient IGT) $[10,11]$. Subjects with persistent IGT also demonstrate loss of the first-phase insulin response indicating early $\beta$-cell dysfunction, while subjects with transient IGT have a normal insulin response [12]. It might be useful to distinguish persistent and transient glucose intolerance on the basis of one single glucose tolerance test. This would enable an intervention programme to target those at the greatest risk of progression to Type 2 diabetes mellitus.

A few studies have tried to identify additional factors improving distinction between transient IGT and persistent IGT $[11,13,14]$. The most important predictors were 2-h blood glucose level, hyperinsulinaemia, and overall obesity [i.e. body mass index (BMI)]. However, both total body fat content and body fat distribution are important risk factors for the development of Type 2 diabetes mellitus [15-17]. Simple anthropometric measures (e.g. waist circumference, skinfold thickness) could provide additional information to measures of overall body fat content (i.e. BMI), and may have potential predictive value in distinguishing between persistent and transient IGT. Indeed, it has been shown that concurrent use of simple anthropometric assessments may provide a more complete picture of risk of abnormal glucose and insulin regulation [18].

The purpose of the present study was to assess whether adding single or multiple anthropometric measurements to oral glucose tolerance testing improved the distinction between transient and persistent IGT in middle-aged men and women. BMI, waist and hip circumference, waist-hip ratio (WHR), sagittal and transverse abdominal diameter and skinfold thickness were used as anthropometric measures.

\section{Patients and methods}

\section{Study design}

The SLIM project (Study on Lifestyle-Intervention and IGT, Maastricht) is a randomized controlled trial, designed to study whether 3 years diet/physical activity intervention programme can improve glucose tolerance and prevent Type 2 diabetes mellitus (DM) in subjects with IGT. The study design is described elsewhere [19]. In brief, subjects with an elevated risk for the presence of disturbances in glucose tolerance (age $>40$ and/or a family history of diabetes), but no known DM, were selected from an existing cohort, monitoring health and disease in the Maastricht population, and invited to undergo a first OGTT. Caucasian subjects with capillary 2-h glucose levels $>7.8 \mathrm{mmol} / \mathrm{l}$, in otherwise good health and willing to participate in a lifestyle intervention programme, were invited for a second OGTT $(n=177)$. During the second OGTT the physical examination included several anthropometric measurements (see below). Final inclusion in the intervention study was based on results of both OGTTs and several exclusion criteria.

In this paper we describe 108 subjects with IGT at the first OGTT, who underwent a second OGTT within 2-4 months after the initial test. Those with impaired fasting glucose (IFG), newly diagnosed Type 2 diabetes and high normal values at the first OGTT were excluded from this analysis $(n=69)$. In total, results are described from 57 men (age $57.4 \pm 1.0$ years, BMI $29.2 \pm 0.5 \mathrm{~kg} / \mathrm{m}^{2}$ ) and 51 women (age $55.1 \pm 1.1$ years, BMI $29.3 \pm 0.5 \mathrm{~kg} / \mathrm{m}^{2}$ ). The Medical Ethical Review Committee of Maastricht University approved the study protocol, and all subjects gave their written informed consent before the start of the study.

\section{Glucose tolerance testing}

Glucose tolerance was tested with a standard OGTT. After an overnight fast (10-12 h), blood samples were drawn, after which the subjects received the glucose load (75 g glucose, dissolved in $250 \mathrm{ml}$ water; AVEBE, Veendam the Netherlands). After $2 \mathrm{~h}$ another blood sample was drawn. During the initial OGTT capillary blood was collected, and blood glucose level was determined with a glucometer Elite (Bayer, Zurich, Switzerland). Test strips are calibrated to give results equivalent to capillary plasma; this means that IGT is defined as fasting $<7.0 \mathrm{mmol} / \mathrm{l}$ and $2 \mathrm{~h} \geq 8.9 \mathrm{mmol} / \mathrm{l}$, but $<12.2 \mathrm{mmol} / \mathrm{l}$ according to the WHO [20]. During the second test, blood glucose levels were determined in venous plasma with a standard enzymatic technique automated on the Cobas Fara centrifugal analyser at 340 nm (Roche Unikit III; Hoffman-La Roche, Basel, Switzerland). During the second OGTT a fasting blood sample was drawn to determine the $\mathrm{HbA}_{1 \mathrm{c}}$ fraction by high-performance liquid chromatography (reference value for our laboratory $4.4-6.2 \%$ ).

It is known that glucose levels are higher in capillary blood compared with venous blood or plasma. To validate this approach we measured the consistency in classification according to the WHO criteria [20] between capillary blood and venous plasma in a distinct group of subjects selected from the same cohort as the present study population. During standard OGTT we simultaneously measured in 245 men and women (age $59.3 \pm 6.8$ years, BMI $28.6 \pm 4.2 \mathrm{~kg} / \mathrm{m}^{2}$ ) venous plasma and capillary blood glucose concentration (with the methods described above). Mean difference between capillary and venous plasma glucose was $0.16 \mathrm{mmol} / 1$ [ $95 \%$ confidence interval (CI) $0.02,0.30]$ and $0.96 \mathrm{mmol} / \mathrm{l}(95 \% \mathrm{CI} 0.68,1.24)$ during fasting 
and at $2 \mathrm{~h}$ post OGTT, respectively. These differences closely match the difference between (capillary and venous plasma) cutoff values used for defining IGT according the WHO (fasting $0.0 \mathrm{mmol} / \mathrm{l}$ and $2 \mathrm{~h} 1.1 \mathrm{mmol} / \mathrm{l}$ ). Consistency in classification according to the WHO criteria between capillary blood and venous plasma was good $(69 \%, \kappa 0.55, P<0.001$ [21]).

\section{Anthropometry}

Body weight was measured with an electronic scale to the nearest $0.1 \mathrm{~kg}$, with the subject wearing only light clothing. Height was measured with the subject standing on the floor without shoes with the back straight against the wall to the nearest $0.5 \mathrm{~cm}$. BMI was calculated as the ratio of the weight and height squared $\left(\mathrm{kg} / \mathrm{m}^{2}\right)$. Skinfold thickness was measured twice using a skinfold calliper at the triceps, biceps, subscapular and suprailiacal region. The sum of peripheral skinfold (triceps and biceps) and the sum of trunk skinfold (subscapular and suprailiacal) was computed. Waist circumference (waist) was measured with the subject in the standing position at the level midway between the lowest rib and iliacal crest to the nearest $0.5 \mathrm{~cm}$; hip circumference was measured at the maximum circumference over the buttocks to the nearest $0.5 \mathrm{~cm}$. WHR was computed as the ratio between waist and hip circumference. Sagittal and transverse abdominal diameter were measured with the subject in a recumbent position, at the level of the crista iliaca to the nearest $\mathrm{mm}$ using a sliding beam calliper. The same person did all the anthropometric measurements.

\section{Classification of subjects}

The results of the second OGTT were interpreted according to the WHO criteria: IGT fasting $<7.0 \mathrm{mmol} / \mathrm{l}, 2 \mathrm{~h} \geq 7.8$ and $<11.1 \mathrm{mmol} / \mathrm{l}$ [20]. In the subsequent (statistical) analysis comparisons were made between subjects returning to normal glucose tolerance at the second test (transient IGT) and subjects remaining impaired glucose tolerant (persistent IGT).

\section{Statistical analysis}

Date are expressed as mean \pm SEM. All variables were checked for normal distribution. Differences between groups were analysed with an unpaired $t$-test. The predictive value of anthropometric variables for having transient or persistent IGT was analysed by means of logistic regression analysis. Dependent (nominal) variable was persistent IGT or not. For each anthropometric variable, logistic regression analysis was carried out using sex, age, family history of diabetes and 2-h glucose at the initial test as covariant. Odds ratios were expressed according to a $1 \mathrm{SD}$ difference in the selected anthropometric variable. Level of significance was set at $P \leq 0.05$. All analyses were performed with Statview 5.0 for Macintosh (SAS, Cary, NC, USA).

\section{Results}

In total 108 subjects, 57 men and 51 women, participated in both OGTTs. Outcome of the second OGTT is depicted in Table 1. Normal glucose tolerance at re-testing was found in
40 subjects $(37 \%)$, IGT in 47 subjects ( $44 \%$ ), impaired fasting glucose in eight subjects $(7 \%)$ and newly diagnosed Type 2 DM in 13 subjects (12\%). When split by sex the number of subjects returning to normal was not different between men and women (see Table 1). Only the data from the 40 subjects returning to normal glucose tolerance at re-testing (transient IGT) and the 47 subjects remaining IGT (persistent IGT) were used in the following analysis.

Average time between the initial OGTT and the second OGTT was $79 \pm 47$ days (mean \pm SD), and no differences in average time between tests were observed between subjects with transient and persistent glucose intolerance (data not shown). Furthermore, no difference in change in body weight between the first and the second OGTT was observed between groups (data not shown).

Anthropometric variables and results of the initial OGTT are depicted in Table 2 for transient IGT and persistent IGT. Post load blood glucose concentrations during the initial OGTT were higher in persistent IGT compared with transient IGT $(P<0.01)$. Fasting blood glucose concentrations during the initial OGTT tended to be higher in persistent IGT compared with transient IGT $(P=0.09)$. Body weight, BMI and age were not different between groups. No significant differences were found in waist circumference, WHR and sagittal and transverse abdominal diameter between subjects with persistent and transient IGT (see Table 2). Subscapular skinfold thickness was higher in persistent IGT compared with transient IGT $(25.4 \pm 1.4 \mathrm{~mm}$ vs. $29.8 \pm 1.2 \mathrm{~mm}$ for transient IGT and persistent IGT, respectively; $P<0.02$ ). The summations of peripheral, truncal and all skinfold measurements were not significant different between transient and persistent glucoseintolerant subjects.

Logistic regression analysis revealed that the 2-h blood glucose level at the initial test was the strongest predictor of persistent IGT [odds ratio (OR) for 1 SD difference 2.32; $P<0.02]$. To evaluate whether anthropometric measurements were of (additional) predictive value in distinguishing between transient and persistent IGT, logistic regression analysis was performed after adjustment for age, sex, family history of DM, and 2-h blood glucose level at the initial test (Table 3). Persistent IGT was predicted by an increased subscapular skinfold (OR for 1 SD difference 1.84; $P<0.05$ ). WHR (OR 1.73), transverse abdominal diameter and sum of truncal skinfolds were also associated with an increased risk of having persistent

Table 1 Results of the second oral glucose tolerance test

\begin{tabular}{lrcc}
\hline & Men & Women & \multicolumn{1}{l}{ All } \\
\hline Normal glucose tolerance & 19 & 21 & $40(37 \%)$ \\
Impaired fasting glucose & 6 & 2 & $8(7 \%)$ \\
Impaired glucose tolerance & 26 & 21 & $47(44 \%)$ \\
Type 2 diabetes mellitus & 6 & 7 & $13(12 \%)$ \\
Total & 57 & 51 & 108 \\
\hline
\end{tabular}

Classification according to the WHO criteria 1999 [20]. 
Table 2 Clinical characteristics of subjects with transient and persistent impaired glucose tolerance (IGT)

\begin{tabular}{llll}
\hline Variable & $\begin{array}{l}\text { Transient IGT } \\
(n=40)\end{array}$ & $\begin{array}{l}\text { Persistent IGT } \\
(n=47)\end{array}$ & $P$-value \\
\hline Sex $(\mathrm{M} / \mathrm{F})$ & $19 / 21$ & $26 / 21$ & \\
Age $($ years $)$ & $56.4 \pm 1.1$ & $56.2 \pm 1.2$ & $\mathrm{NS}$ \\
Weight $(\mathrm{kg})$ & $81.6 \pm 2.4$ & $83.8 \pm 1.7$ & $\mathrm{NS}$ \\
BMI $\left(\mathrm{kg} / \mathrm{m}^{2}\right)$ & $28.4 \pm 0.6$ & $29.4 \pm 0.6$ & $\mathrm{NS}$ \\
Waist $(\mathrm{cm})$ & $97.8 \pm 1.8$ & $101 \pm 1.4$ & $\mathrm{NS}$ \\
WHR & $0.94 \pm 0.01$ & $0.97 \pm 0.01$ & 0.07 \\
Sagittal abd. dm $(\mathrm{mm})$ & $233 \pm 5.3$ & $242 \pm 3.8$ & 0.07 \\
Transverse abd. dm (mm) & $362 \pm 6$ & $376 \pm 4.6$ & 0.07 \\
Biceps SKF $(\mathrm{mm})$ & $15.0 \pm 1.1$ & $15.6 \pm 1.0$ & $\mathrm{NS}$ \\
Triceps SKF $(\mathrm{mm})$ & $19.4 \pm 1.6$ & $19.3 \pm 1.3$ & $\mathrm{NS}$ \\
Peripheral SKF $(\mathrm{mm})$ & $34.4 \pm 2.6$ & $34.9 \pm 2.2$ & $\mathrm{NS}$ \\
Subscapular SKF $(\mathrm{mm})$ & $25.4 \pm 1.4$ & $29.8 \pm 1.2$ & 0.02 \\
Supra-iliacal SKF $(\mathrm{mm})$ & $29.7 \pm 1.5$ & $31.3 \pm 1.1$ & $\mathrm{NS}$ \\
Truncal SKF $(\mathrm{mm})$ & $55.1 \pm 2.7$ & $61.1 \pm 2.0$ & 0.07 \\
Sum of SKF $(\mathrm{mm})$ & $89.5 \pm 4.7$ & $96.0 \pm 3.8$ & $\mathrm{NS}$ \\
HbA (\%) & $5.8 \pm 0.1$ & $5.8 \pm 0.1$ & $\mathrm{NS}$ \\
Initial OGTT & & & \\
Fasting glucose $(\mathrm{mmol} / \mathrm{l})$ & $5.6 \pm 0.1$ & $5.8 \pm 0.1$ & 0.09 \\
2-h glucose $(\mathrm{mmol} / \mathrm{l})$ & $9.8 \pm 0.1$ & $10.2 \pm 0.1$ & $<0.01$ \\
\hline
\end{tabular}

Data are expressed as mean \pm SEM. BMI, Body mass index; WHR, waist-hip ratio; abd. dm, abdominal diameter; SKF, skinfold thickness; NS, not significant.

\begin{tabular}{lcccl}
\hline & (SD) & OR & $95 \%$ CI & $P$-value \\
\hline Weight & $(13.4 \mathrm{~kg})$ & 1.08 & $0.66-1.76$ & NS \\
BMI & $\left(3.8 \mathrm{~kg} / \mathrm{m}^{2}\right)$ & 1.23 & $0.79-1.89$ & NS \\
Waist & $(10.3 \mathrm{~cm})$ & 1.34 & $0.82-2.21$ & NS \\
WHR & $(0.075)$ & 1.73 & $0.90-3.29$ & 0.09 \\
Sagittal abd. dm & $(29.5 \mathrm{~mm})$ & 1.29 & $0.81-2.04$ & NS \\
Transverse abd. dm & $(34.8 \mathrm{~mm})$ & 1.52 & $0.89-2.58$ & NS \\
Biceps SKF & $(6.7 \mathrm{~mm})$ & 1.32 & $0.72-2.42$ & NS \\
Triceps SKF & $(9.3 \mathrm{~mm})$ & 1.28 & $0.58-2.83$ & NS \\
Peripheral SKF & $(15.3 \mathrm{~mm})$ & 1.35 & $0.65-2.80$ & NS \\
Subscapular SKF & $(8.5 \mathrm{~mm})$ & 1.84 & $1.06-3.19$ & 0.03 \\
Supra-iliacal SKF & $(8.4 \mathrm{~mm})$ & 1.12 & $0.70-1.79$ & NS \\
Truncal SKF & $(15.3 \mathrm{~mm})$ & 1.47 & $0.88-2.47$ & NS \\
Sum of SKF & $(27.7 \mathrm{~mm})$ & 1.47 & $0.83-2.61$ & NS \\
\hline
\end{tabular}

Odds ratios (OR) and $95 \%$ confidence interval $(95 \% \mathrm{CI})$ for persistent impaired glucose tolerance, for a 1 SD difference in selected variables (adjusted for sex, age, family history of DM and 2-h glucose at initial test). BMI, Body mass index; WHR, waist-hip ratio; abd. $\mathrm{dm}$, abdominal diameter; SKF, skinfold thickness; NS, not significant.
IGT, but ORs were not significantly different from 1. Body weight, BMI, waist circumference, sagittal abdominal diameter and other skinfold thickness measurements were not predictive in this group of subjects.

\section{Discussion}

The main novel finding of the present study is that subscapular skinfold thickness was a predictor of the presence of persistent IGT, independent of other variables including 2-h blood glu- cose level at the initial OGTT, age, sex and family history of diabetes, while other indices of obesity (i.e. BMI, waist) were not, or only weak predictors of persistent IGT. Because subscapular skinfold thickness is related to the subcutaneous fat depot, these data suggest that subcutaneous adipose tissue accumulation, especially in the truncal and central regions, is linked to disturbances in glucose tolerance.

The population described in the present study is a subpopulation from a larger lifestyle-intervention trial (SLIM). Subjects do not necessary reflect the general population, as they were 
selected to participate in a 3-year lifestyle-intervention trial. Furthermore, the size of the population was relatively small $(n=108)$. However, we do not believe these limitations affect our main conclusions.

The OGTT is considered the gold standard in diagnosing glucose intolerance. However, the reproducibility is rather poor, because of the narrow range of the 2-h blood glucose value used for defining IGT $(7.8-11.1 \mathrm{mmol} / \mathrm{l})$. Rates of reversion to normal glucose tolerance of one-third to one-half are reported for subjects with IGT $[8,9]$. This is in accordance with the results of the present study. In total, 40 out of 108 subjects $(37 \%)$ reverted to normal glucose tolerance at retesting (transient IGT); whereas 47 subjects $(44 \%)$ remained glucose intolerant (persistent IGT). This may reflect both regression to the mean and a lesser degree of arousal or stress at the second test.

We determined glucose tolerance during the first test in capillary blood and during the second test in venous plasma. It is known that glucose levels are higher in capillary blood compared with venous blood or plasma. However, for classification of the subjects we used, at both occasions, the appropriate set of criteria according to the WHO, i.e. capillary criteria for the first OGTT and venous plasma criteria for the second test [20]. We validated this in a comparable population and observed a good consistency in classification $(69 \%, \kappa 0.55$, $P<0.001$ [21]). These results indicate that the difference in methods used for measuring blood glucose during OGTT do not change the interpretation of our data.

Although transient IGT indicates a predisposition to diabetes [10], the incidence of diabetes is higher in subjects with persistent IGT $[11,22]$. Factors predicting persistent glucose intolerance include increased insulin levels, obesity, and positive family history of diabetes $[13,14]$. In the present study, subscapular skinfold thickness was significantly associated with an increased risk of persistent IGT, even after correction for 2-h blood glucose levels at the initial test, while measures of (abdominal) obesity were not or only weakly associated with an increased risk of having persistent IGT. These results suggest that body fat distribution is more important than total body fat mass in relation to transient or persistent glucose intolerance. Although waist circumference is an important risk factor for Type 2 DM [15], it only predicted weakly the presence of persistent IGT. However, our data were obtained in a relatively small group of middle-aged people $(n=108$; 56.3 years) with an elevated BMI $\left(29.2 \mathrm{~kg} / \mathrm{m}^{2}\right)$. It would be interesting to evaluate the performance of measurement of subscapular skinfold thickness and other anthropometric measures in a larger sample.

Whether visceral or subcutaneous abdominal fat is most strongly linked to insulin resistance is still unanswered [23]. Excess supply of free fatty acids (FFA) from visceral fat directly via the portal vein to the liver can have several adverse effects on hepatic metabolism, leading to hyperglycaemia and hyperinsulinaemia [24]. However, although subcutaneous abdominal adipose tissue may be metabolically less active, it is a considerably larger fat mass than the visceral fat compartment [25], resulting in a large release of FFA into the circulation. Abate et al. [25] concluded that subcutaneous truncal fat plays a major role in obesity-related insulin resistance in men, whereas intraperitoneal fat and retroperitoneal fat were less important. In our study subscapular skinfold thickness, an estimate of subcutaneous (central) fat, predicted the presence of persistent glucose intolerance even after correction for 2-h blood glucose level during the first test. Measures of total fat mass, as BMI, and others reflecting deep visceral fat mass, were less predictive of persistent glucose intolerance. This agrees with previous studies showing an association between (subscapular) skinfold thickness and glucose tolerance $[17,18,26]$. This suggests that the subcutaneous abdominal fat depot influences disturbances in glucose homeostasis among overweight subjects.

In summary, our results revealed that besides 2-h blood glucose at the initial OGTT, subscapular skinfold thickness was the best predictor of persistent IGT. In middle-aged men and women, simple anthropometric measurements may improve the discrimination between subjects with transient and persistent IGT, enabling identification of those most at risk of Type 2 diabetes.

\section{Acknowledgements}

This work was supported by a grant of the Dutch Diabetes Research Foundation (DFN 98.901) and a grant of the Netherlands Organization for Scientific Research (ZonMW 94035-034). Furthermore, we thank Jos Stegen for his analytical support and Rob van Dam for his support during the statistical analysis.

\section{References}

1 Unwin N, Shaw J, Zimmet P, Alberti KG. Impaired glucose tolerance and impaired fasting glycaemia: the current status on definition and intervention. Diabet Med 2002; 19: 708-723.

2 Edelstein SL, Knowler WC, Bain RP, Andres R, Barrett-Connor EL, Dowse GK et al. Predictors of progression from impaired glucose tolerance to NIDDM: an analysis of six prospective studies. Diabetes 1997; 46: 701-710.

3 de Vegt F, Dekker JM, Jager A, Hienkens E, Kostense PJ, Stehouwer $\mathrm{CD}$ et al. Relation of impaired fasting and postload glucose with incident type 2 diabetes in a Dutch population: The Hoorn Study. JAMA 2001; 285: 2109-2113.

4 Chu NF, Lee MM, Wang DJ, Chen LM, Ding YA, Shieh SM. The interrelationship between impaired glucose tolerance and other risk factors for cardiovascular disease: is it a predictor for cardiovascular disease? J Clin Epidemiol 1994; 47: 485-493.

5 Rodriguez BL, Curb JD, Burchfiel CM, Huang B, Sharp DS, Lu GY et al. Impaired glucose tolerance, diabetes, and cardiovascular disease risk factor profiles in the elderly. The Honolulu Heart Program. Diabetes Care 1996; 19: 587-590.

6 Tuomilehto J, Lindstrom J, Eriksson JG, Valle TT, Hamalainen H, Ilanne-Parikka $\mathrm{P}$ et al. Prevention of type 2 diabetes mellitus by changes in lifestyle among subjects with impaired glucose tolerance. N Engl J Med 2001; 344: 1343-1350. 
7 Knowler WC, Barrett-Connor E, Fowler SE, Hamman RF, Lachin JM, Walker EA et al. Reduction in the incidence of type 2 diabetes with lifestyle intervention or metformin. N Engl J Med 2002; 346: 393-403.

8 Riccardi G, Vaccaro O, Rivellese A, Pignalosa S, Tutino L, Mancini M. Reproducibility of the new diagnostic criteria for impaired glucose tolerance. Am J Epidemiol 1985; 121: 422-429.

9 Ko GT, Chan JC, Woo J, Lau E, Yeung VT, Chow CC et al. The reproducibility and usefulness of the oral glucose tolerance test in screening for diabetes and other cardiovascular risk factors. Ann Clin Biochem 1998; 35: 62-67.

10 Saad MF, Knowler WC, Pettitt DJ, Nelson RG, Bennett PH. Transient impaired glucose tolerance in Pima Indians: is it important? Br Med J 1988; 297: 1438-1441.

11 Motala AA, Omar MA, Gouws E. Transient impaired glucose tolerance in South African Indians does not carry a risk for progression to NIDDM. Diabetes Care 1997; 20: 1101-1107.

12 Davies MJ, Rayman G, Grenfell A, Gray IP, Day JL, Hales CN. Loss of the first phase insulin response to intravenous glucose in subjects with persistent impaired glucose tolerance. Diabet Med 1994; 11: 432-436.

13 Bourn DM, Williams SM, Mann JI. Distinguishing between persistent and transient impaired glucose tolerance using a prediction model. Diabet Med 1992; 9: 744-748.

14 Qiao Q, Keinanen-Kiukaanniemi S, Rajala U, Uusimaki A, Kivela SL. Risk for diabetes and persistent impaired glucose tolerance among middle-aged Finns. Diabetes Res Clin Pract 1996; 33: 191-198.

15 Seidell JC, Han TS, Feskens EJ, Lean ME. Narrow hips and broad waist circumferences independently contribute to increased risk of non-insulin-dependent diabetes mellitus. J Intern Med 1997; 242: 401-406.

16 Wei M, Gaskill SP, Haffner SM, Stern MP. Waist circumference as the best predictor of noninsulin dependent diabetes mellitus (NIDDM) compared to body mass index, waist/hip ratio and other anthropometric measurements in Mexican Americans-a 7-year prospective study. Obes Res 1997; 5: 16-23.

17 Feskens EJ, Kromhout D. Effects of body fat and its development over a ten-year period on glucose tolerance in euglycaemic men: the Zutphen Study. Int J Epidemiol 1989; 18: 368-373.

18 Sievenpiper JL, Jenkins DJ, Josse RG, Leiter LA, Vuksan V. Simple skinfold-thickness measurements complement conventional anthropometric assessments in predicting glucose tolerance. Am J Clin Nutr 2001; 73: 567-573.

19 Mensink M, Blaak EE, Feskens EJM, de Bruin TWA, Saris WHM. Study on lifestyle intervention and impaired glucose tolerance: study design. Int J Obes Relat Metab Disord 2000; 24: S93 (Abstract).

20 World Health Organization. Definition, Diagnosis and Classification of Diabetes Mellitus. Report of a WHO Consultation. Part 1: Diagnosis and Classification of Diabetes Mellitus. Publication WHO/NCD/NCS/99.2. Geneva: WHO, 1999.

21 Kruijshoop M, Feskens EJM, Blaak EE, Heine RJ, de Bruin TWA. Validation of capillary glucose measurements to detect type 2 diabetes mellitus in the general population: The CoDAM-study. Diabetologia 2002; 42: A98 (Abstract).

22 Nagi DK, Knowler WC, Charles MA, Liu QZ, Hanson RL, McCance DR et al. Early and late insulin response as predictors of NIDDM in Pima Indians with impaired glucose tolerance. Diabetologia 1995; 38: 187-192.

23 Frayn KN. Visceral fat and insulin resistance-causative or correlative? Br J Nutr 2000; 83: S71-77.

24 Björntorp P. Regional fat distribution-implications for type II diabetes. Int J Obes Relat Metab Disord 1992; 16: S19-27.

25 Abate N, Garg A, Peshock RM, Stray-Gundersen J, Grundy SM. Relationships of generalized and regional adiposity to insulin sensitivity in men. J Clin Invest 1995; 96: 88-98.

26 Harlan LC, Harlan WR, Landis JR, Goldstein NG. Factors associated with glucose tolerance in adults in the United States. Am J Epidemiol 1987; 126: 674-684. 